\title{
ARTICLE
}

\section{Structural prerequisites for G-protein activation by the neurotensin receptor}

\author{
Brian E. Krumm¹, Jim F. White ${ }^{1}$, Priyanka Shah ${ }^{1} \&$ Reinhard Grisshammer ${ }^{1}$
}

We previously determined the structure of neurotensin receptor NTSR1 in an active-like conformation with six thermostabilizing mutations bound to the peptide agonist neurotensin. This receptor was unable to activate $G$ proteins, indicating that the mutations restricted NTSR1 to relate agonist binding to G-protein activation. Here we analyse the effect of three of those mutations (E166A ${ }^{3.49}$, L310A $^{6.37}$, F358 $A^{7.42}$ ) and present two structures of NTSR1 able to catalyse nucleotide exchange at $\mathrm{G} \alpha$. The presence of $\mathrm{F}_{358}{ }^{7.42}$ causes the conserved W $321^{6.48}$ to adopt a side chain orientation parallel to the lipid bilayer sealing the collapsed $\mathrm{Na}^{+}$ion pocket and linking the agonist with residues in the lower receptor part implicated in GPCR activation. In the intracellular receptor half, the bulkier $L 310^{6.37}$ side chain dictates the position of $R 167^{3.50}$ of the highly conserved D/ERY motif. These residues, together with the presence of $\mathrm{E} 166^{3.49}$ provide determinants for G-protein activation by NTSR1.

\footnotetext{
${ }^{1}$ Membrane Protein Structure Function Unit, National Institute of Neurological Disorders and Stroke, National Institutes of Health, Department of Health and Human Services, 5625 Fishers Lane, Rockville, Maryland 20852, USA. Correspondence and requests for materials should be addressed to R.G.

(email: rkgriss@helix.nih.gov).
} 
$\mathrm{G}$ PCRs are highly versatile signalling molecules that modulate second messenger responses in the cell. Binding of an extracellular agonist leads to conformational changes in the receptor, triggering activation of associated signalling partners on the intracellular side of the membrane. GPCRs are no longer thought to be two-state switches (inactive or active, although rhodopsin may come close to this definition) but are able to sample many conformational states depending on the bound ligand, associated signalling partner and membrane environment ${ }^{1}$. Recent advances in the structural biology of GPCRs have resulted in high-resolution snapshots of inactive ${ }^{2}$, active-like $^{3}$ and active receptor conformations ${ }^{4-7}$.

Our research focuses on understanding the structural and functional requirements for the activation of the neurotensin receptor 1 (NTSR1, ref. 8). Its agonist ligand neurotensin (NTS) is a 13-amino acid peptide that functions as a neurotransmitter and a hormone in the nervous system and in peripheral tissues ${ }^{9}$. NTS has a wide range of biological activities with important aspects in antinociception, cancer cell growth and the pathogenesis of schizophrenia ${ }^{10,11}$. Most of the known agonist effects of NTS are mediated through NTSR1 (refs 8,11).

Previously, we determined the structure of NTSR1 bound to $\mathrm{NTS}_{8-13}$ (Arg-Arg-Pro-Tyr-Ile-Leu) in an active-like conformation with six thermostabilizing mutations providing insight into the binding mode of a peptide agonist. This receptor was unable to catalyse nucleotide exchange at the $\mathrm{G} \alpha$ subunit, indicating that some of the stabilizing mutations may have restricted the ability of NTSR1 to relate agonist binding to the activation of G protein. Here we analyse the effect of three of those six mutations $\left(E 166 \mathrm{~A}^{3.49}\right.$, $\mathrm{L} 310 \mathrm{~A}^{6.37}, \mathrm{~F} 358 \mathrm{~A}^{7.42}$ ) on G-protein activation and present structures of active-like NTSR1 that are able to activate G protein. Unique to these structures is the presence of a phenylalanine at position 7.42 causing the conserved W $321^{6.48}$ to adopt a side chain rotamer conformation parallel to the lipid bilayer, which has not been seen in any GPCR structures to date. The W $321^{6.48}$ residue seals the top of the collapsed $\mathrm{Na}^{+}$ion-binding pocket and along with the $\mathrm{F} 358^{7.42}$ residue links the agonist peptide, bound closer to the extracellular surface, with residues in the lower part of NTSR1 that are implicated in conformational changes for GPCR activation. In the intracellular receptor half, the bulkier $\mathrm{L} 310^{6.37}$ side chain dictates the position of $R 167^{3.50}$ of the highly conserved D/ERY motif. This, together with the presence of the neighbouring E166 3.49 provides determinants for G-protein activation.

\section{Results}

NTSR1 constructs used in this study. Here, we describe structural, biochemical and pharmacological data of several NTSR1 mutants (see Supplementary Tables 1 and 2) with either wild-type intracellular loop 3 (ICL3), or with most of ICL3 replaced by T4 lysozyme (T4L). In the Methods section, we distinguish between NTSR1 constructs containing the wild-type ICL3 sequence or T4L. In the main text, we use only one name for a particular construct for ease of reading. For example, NTSR1-ELF refers interchangeably to NTSR1-ELF-T4L and NTSR1-ELF, the latter containing the wild-type ICL3, not T4L. The identity of the respective construct is evident from the context of writing. Protein crystals were obtained with receptors where most of ICL3 was replaced by T4L. Pharmacological and biochemical experiments were conducted with receptors containing the wild-type ICL3 sequence, but also included T4L variants for comparison. In Figures and Tables relating to biochemical and pharmacological data, the identity of constructs is unambiguously specified.

Active-like NTSR1 mutants which activate Gq protein. We previously reported the crystal structure of NTSR1-GW5 (ref. 3) containing six stabilizing mutations (A86L ${ }^{1.54}, \mathrm{E}^{266 \mathrm{~A}^{3.49}}$, $\mathrm{G} 215 \mathrm{~A}^{\mathrm{ECL} 2}$, L310A $\mathrm{A}^{6.37}$, F $358 \mathrm{~A}^{7.42}$ and V360A $\mathrm{A}^{7.44}$; ref. 12; superscripts are the Ballesteros-Weinstein numbers ${ }^{13}$ ). NTSR1GW5 displayed features of an active-like receptor such as an outward-tilted transmembrane helix (TM) 6 at the cytoplasmic surface and key conserved residues in positions characteristic for active and/or active-like but not for inactive GPCRs. NTSR1GW5 did not catalyse nucleotide exchange at G $\alpha \mathrm{q}$ in response to NTS in G-protein-coupling assays (Fig. 1) ${ }^{3}$, suggesting that some of the stabilizing mutations have limited the ability of NTSR1GW5 to activate G protein. On the basif of their location, we assumed that the mutations E166A $\mathrm{A}^{3.49}, \mathrm{~L}_{310 \mathrm{~A}^{6.37}}$ and F358A 7.42 affected the NTSR 1 activation state, whereas the involvement of the mutations $\mathrm{A} 86 \mathrm{~L}^{1.54}, \mathrm{G} 215 \mathrm{~A}^{\mathrm{ECL} 2}$ and $\mathrm{V} 360 \mathrm{~A}^{7.44}$ was not obvious $^{3}$. We therefore reverted the three mutations $\mathrm{E} 166 \mathrm{~A}^{3.49}$, $\mathrm{L}_{310 \mathrm{~A}^{6.37}}$ and F358A $\mathrm{A}^{7.42}$ to wild-type residues, alone or in combination (Supplementary Table 1), to analyse their role in G-protein activation. In contrast to NTSR1-GW5, the triple revertant NTSR1-ELF (with E166, L310, F358) was able to stimulate nucleotide exchange at $\mathrm{G} \alpha \mathrm{q}$ to almost wild-type level (Fig. 1, Supplementary Fig. 1, Supplementary Table 2). The double revertant NTSR1-EL (with E166 and L310) showed reduced activity in nucleotide exchange assays, but highlights the importance of E166 3.49 , of the highly conserved D/ERY motif, along with the neighbouring $\mathrm{L} 310^{6.37}$ for G-protein activation (Fig. 1).

Pharmacological characterization of NTSR1-LF and NTSR1-ELF. Ligand-binding experiments (Supplementary Table 2) showed that the apparent affinity of NTSR1-LF and NTSR1-ELF for the agonist NTS was comparable to that of the wild-type receptor and NTSR1GW5. The agonist-binding experiments using wild-type NTSR1 were conducted at equilibrium. In contrast, binding of $\left[{ }^{3} \mathrm{H}\right] \mathrm{NTS}$ to the NTSR1 mutants did not reach equilibrium within the incubation time because of the slow agonist off-rates. The apparent $\mathrm{IC}_{50}$ values for the antagonist SR48692 (ref. 14) were 3-5-fold higher than the corresponding wild-type value, but more than 20-fold lower than the value for NTSR1-GW5. The shift in $\mathrm{IC}_{50}$ values may be caused

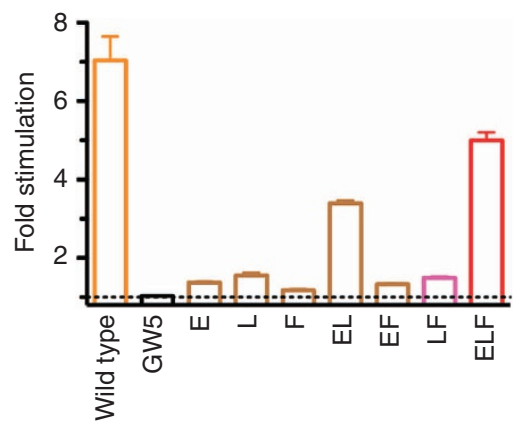

Figure 1 | Mutational analysis of NTSR1 for activation of G protein. Agonist-stimulated activation of Gq: GDP/ $\left.{ }^{35} \mathrm{~S}\right] \mathrm{GTP} \gamma \mathrm{S}$ exchange assays contained purified Gq protein, $\left.{ }^{35} \mathrm{~S}\right] \mathrm{GTP} \gamma \mathrm{S}$, insect cell membranes with NTSR1 and saturating concentrations of NTS $(20 \mu \mathrm{M})$. Fold stimulation of the exchange of GDP for $\left[{ }^{35} \mathrm{~S}\right] \mathrm{GTP} \gamma \mathrm{S}$ at Gq in the presence of NTS is compared with the nucleotide exchange in the absence of ligand (number of independent experiments: wild-type NTSR1 $n=7$; NTSR1-GW5 $n=1$; NTSR1-E $n=4$; NTSR1-L $n=5$; NTSR1-F $n=4$; NTSR1-EL $n=5$; NTSR1-EF $n=4$; NTSR1-LF $n=7$; NTSR1-ELF $n=6$ ). A value of 1 (dotted line) indicates the absence of receptor-catalysed nucleotide exchange. All G-protein activation experiments were conducted with NTSR1 constructs (containing the wild-type ICL3, not T4L) in urea-washed P2 insect cell membranes. The identity of the NTSR1 constructs is given in Supplementary Table 1. Error bars correspond to s.e.m. 
partly by a change in affinity of SR48692 to the NTSR1 mutants, and/or because SR48692 and $\left[{ }^{3} \mathrm{H}\right] \mathrm{NTS}$ binding to the NTSR1 mutants did not reach equilibrium under the experimental conditions because of the change in the off-rate of $\left[{ }^{3} \mathrm{H}\right]$ NTS for the receptor mutants.

NTSR1-GW5, NTSR1-LF and NTSR1-ELF showed reduced sensitivity of agonist binding in the presence of $\mathrm{Na}^{+}$ions (Supplementary Table 2) possibly indicating a high-affinity agonist conformation of the NTSR1 mutants. In contrast to wild-type NTSR1, the presence of $\mathrm{NaCl}$ did not increase the dissociation of $\left[{ }^{3} \mathrm{H}\right] \mathrm{NTS}$ from NTSR1-LF, as was also observed with NTSR1-GW5 (ref. 3). However, $\mathrm{NaCl}$ did increase the dissociation of $\left[{ }^{3} \mathrm{H}\right]$ NTS from NTSR1-ELF, albeit not as pronounced as that seen with the wild-type receptor (Supplementary Fig. 1). The crystal structures of NTSR1-LFT4L and NTSR1-ELF-T4L cannot explain the observed differences in the $\mathrm{Na}^{+}$ion-dependent kinetics of NTS dissociation from NTSR1-LF and NTSR1-ELF. However, NTSR1-ELF may be more dynamic than NTSR1-LF, indicated by its lower thermal stability (Supplementary Table 3) and thus higher flexibility, accounting for the observed differences of the kinetic properties of both receptor mutants.

In G-protein-coupling assays, NTSR1-LF had moderate ability to activate the G protein. NTSR1-ELF was able to stimulate nucleotide exchange at $\mathrm{G} \alpha \mathrm{q}$ to almost wild-type level (Fig. 1, Supplementary Fig. 1, Supplementary Table 2). The doseresponse curves for the determination of the half maximal effective concentration of NTS on the exchange of GDP for $\mathrm{GTP} \gamma \mathrm{S}$ on $\mathrm{Gq}\left(\mathrm{EC}_{50}\right.$ values) were multiphasic (Hill slope $<1$ ) for NTSR1-ELF and wild-type NTSR1, indicating high and low affinity agonist-binding sites at non-saturating G-protein concentrations. In contrast, NTSR1-LF showed monophasic curves indicating a single class of binding sites. The $\mathrm{EC}_{50}$ value for wildtype NTSR1 is 20 -fold higher than the $K_{i}$ value determined in homologous $\left[{ }^{3} \mathrm{H}\right] \mathrm{NTS} / \mathrm{NTS}$ competition experiments, possibly because the affinity of NTS for wild-type NTSR1 is affected by the presence of $\mathrm{Na}^{+}$ions (discussed above) reducing the efficacy of G-protein activation at the $\mathrm{NaCl}$ concentrations used in the nucleotide exchange reactions. The differences between $\mathrm{EC}_{50}$ and $\mathrm{K}_{\mathrm{i}}$ values persist for NTSR1-LF and NTSR1-ELF, although they become smaller (15-fold and 4-fold for NTSR1-LF and NTSR1ELF, respectively). As the NTSR1 mutants show reduced sensitivity of agonist binding in the presence of $\mathrm{Na}^{+}$ions, the above explanation(s) may not suffice, but, in addition, possibly reflect the consequence of non-saturating G-protein concentrations in the GDP/GTP $\gamma \mathrm{S}$ exchange assays (which may also apply to wild-type NTSR1).

Architecture of NTSR1-ELF and NTSR1-LF. To understand the structural implications of E166 $3.49, \mathrm{~L} 310^{6.37}$ and F $358^{7.42}$ on the activation of $\mathrm{G}$ protein, we determined the structure of NTSR1ELF to $2.9 \AA$ resolution (Table 1). In addition, we determined the structure of NTSR1-LF (with L310 and F358) to $2.6 \AA$ resolution. This latter mutant has moderate ability to activate $G$ protein (Fig. 1) likely because of the absence of the E166 ${ }^{3.49}$ side chain. The comparison with NTSR1-ELF is thus expected to provide insight into the structural role of E166 ${ }^{3.49}$, a residue critical for governing receptor conformation and G-protein recognition ${ }^{15}$. For both constructs, we obtained crystals using the lipidic cubic phase crystallization method in combination with the chimeric T4 lysozyme approach to improve the probability of obtaining well-diffracting crystals.

Superposition of NTSR1-ELF or NTSR1-LF with NTSR1-GW5 reveals that the structures are overall similar (root mean squared deviation with values of $0.7 \AA$ for $\mathrm{C} \alpha$ atoms, excluding T4
Table 1 | Data collection and refinement statistics.

\begin{tabular}{|c|c|c|}
\hline & NTSR1-LF-T4L & NTSR1-ELF-T4L \\
\hline \multicolumn{3}{|l|}{ Data collection } \\
\hline Space group & P $2{ }_{1} 22_{1}$ & P $2{ }_{1} 22_{1}$ \\
\hline Mol/ASU & 1 & 1 \\
\hline \multicolumn{3}{|l|}{ Cell dimensions } \\
\hline$a, b, c(\AA)$ & $49.8,88.4,161.3$ & $49.1,88.1,161.3$ \\
\hline$\alpha, \beta, \gamma\left(^{\circ}\right)$ & $90,90,90$ & $90,90,90$ \\
\hline \multirow[t]{2}{*}{ Resolution $(\AA)$} & $34.0-2.60$ & $45.0-2.90$ \\
\hline & $(2.69-2.60)^{\star}$ & $(3.00-2.90)^{\star}$ \\
\hline$R_{\text {merge }}(\%)$ & $0.15(0.73)$ & $0.15(0.80)$ \\
\hline Mean $I / \sigma(I)$ & $10.9(1.5)$ & $9.3(1.5)$ \\
\hline Completeness (\%) & $99.4(98.6)$ & $90.2(87.4)$ \\
\hline Redundancy & $7.2(4.0)$ & $6.6(3.7)$ \\
\hline \multicolumn{3}{|l|}{ Refinement } \\
\hline Resolution $(\AA)$ & $34.0-2.60$ & $45.0-2.90$ \\
\hline No. of total reflections & $161,974(8,709)$ & $96,173(5,081)$ \\
\hline No. of unique reflections & $22,562(2,166)$ & $14,602(1,371)$ \\
\hline$R_{\text {work }} / R_{\text {free }}(\%)$ & $23.2 / 28.0$ & $23.1 / 28.1$ \\
\hline \multicolumn{3}{|l|}{ No. of atoms } \\
\hline Protein & 3,714 & 3,666 \\
\hline Ligand & 58 & 58 \\
\hline Water & 55 & 10 \\
\hline \multicolumn{3}{|l|}{$B$-factors $\left(\AA^{2}\right)$} \\
\hline NTSR1-T4L & 59.8 & 71.8 \\
\hline NTSR1 & 66.5 & 78.9 \\
\hline $\mathrm{T} 4 \mathrm{~L}$ & 47.7 & 58.7 \\
\hline NTS $_{8-13}$ & 56.6 & 65.5 \\
\hline Water & 53.4 & 54.1 \\
\hline \multicolumn{3}{|l|}{ R.m.s. deviations } \\
\hline Bond lengths $(\AA)$ & 0.007 & 0.006 \\
\hline Bond angles $\left({ }^{\circ}\right)$ & 1.185 & 1.01 \\
\hline
\end{tabular}

lysozyme) indicating active-like NTSR1 conformations (Fig. 2). Despite the overall similar architecture of the three NTSR1 structures, NTSR1-ELF and NTSR1-LF differ from NTSR1-GW5 in a number of regions. The amino $(\mathrm{N})$ terminus adopts a short helix (S53-L55) and is, compared with NTSR1-GW5, extended by two residues (G50 and P51) in NTSR1-ELF and three residues (A49, G50 and P51) in NTSR1-LF, providing additional contacts to extracellular loop (ECL) 2. ECL3 (residues I334-T340) of NTSR1-ELF and NTSR1-LF is shifted slightly towards the receptor core by $\sim 2.5 \AA$ (Fig. 2). Subtle, yet distinct differences exist in the $\mathrm{NTS}_{8-13}$ binding mode (Supplementary Tables 4-7). Its R8 side chain is in strong hydrogen bond-mediated contact with D54 and D56 of the receptor N terminus. The R8 side chain in NTSR1-LF (but not in NTSR1-ELF) is also connected to TM7 through water-mediated hydrogen bonds to D345 ${ }^{7.29}$. The R9 side chain also forms a strong hydrogen bond with the main chain oxygen of I334 of ECL3. Overall, NTS $_{8-13}$ engages in more hydrogen bond-mediated interactions with NTSR1-LF and NTSR1-ELF compared with NTSR1-GW5 (Supplementary Tables 4-7).

On the intracellular side, the ends of TM3 of NTSR1-LF and NTSR1-ELF have shifted outward, whereas the ends of TM5 and TM6 have moved towards the receptor core (Fig. 2, Supplementary Table 8) compared with NTSR1-GW5. In addition, the relative positions between TMs within a given receptor have changed. TM3 and TM6 are positioned closer to each other, whereas TM5 and TM6 have shifted away from each other compared with NTSR1-GW5. Of the intracellular loops, 

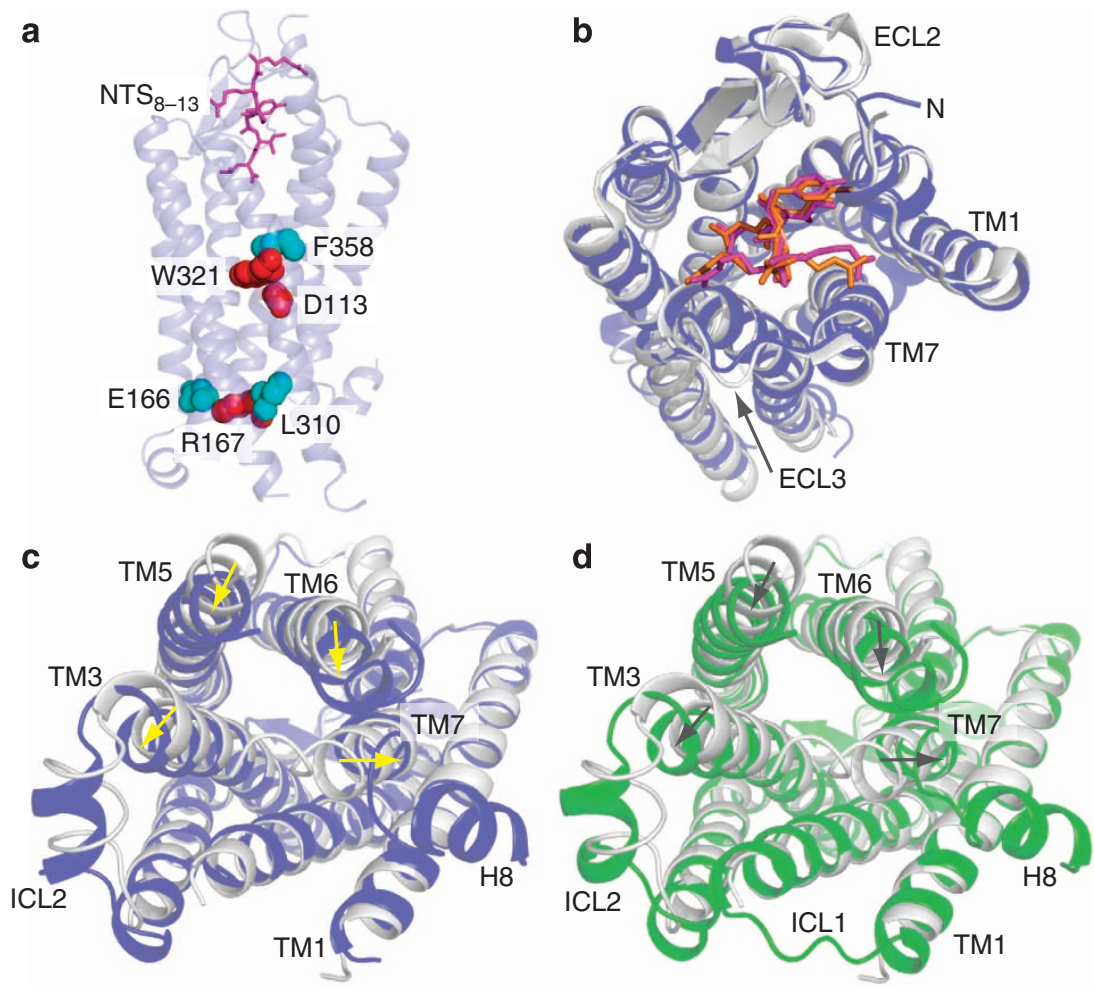

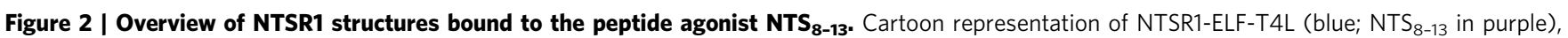
NTSR1-LF-T4L (green) and NTSR1-GW5-T4L (grey, NTS 8 -13 in orange, PDB code 4GRV). NTS 8 -13 is depicted as a stick model. (a) Side view of NTSR1-ELFT4L. Residues E166 ${ }^{3.49}, \mathrm{~L} 310^{6.37}$ and F358 7.42 are shown as cyan spheres; residues D1132.50, W3216.48 and R167 3.50 are depicted in red. (b) Extracellular view. An arrow indicates ECL3, which is shifted towards the receptor core in NTSR1-ELF-T4L. (c,d) Intracellular view. Arrows indicate the position shift of the intracellular ends of TM3, TM5, TM6 and TM7 of NTSR1-ELF-T4L (c) and NTSR1-LF-T4L (d) compared with NTSR1-GW5-T4L. ICL1 is disordered in NTSR1-ELF-T4L. In contrast to NTSR1-GW5-T4L, NTSR1-ELF-T4L and NTSR1-LF-T4L have a short helix H8. T4L has been omitted from the intracellular view for clarity.

ICL1 showed electron density for the main chain atoms in NTSR1-LF but not in NTSR1-ELF. ICL2, thought to be important for G-protein coupling, adopts a two-turn $\alpha$ helix in a slightly different position compared with the $\pi$ helix seen in NTSR1-GW5 (Fig. 2). The structural significance of this observation for the ability of NTSR1 to activate G protein is unclear, as ICL2 adopts an $\alpha$-helical structure in the active $\beta_{2}$-adrenergic receptor-Gs complex $^{7}$ and in the inactive $\beta_{1}$ AR structure ${ }^{16}$ but is an extended loop in the inactive $\beta_{2} \mathrm{AR}$ structure ${ }^{17}$.

Transmembrane helix 7 and helix 8. In contrast to NTSR1GW5, TM7 shows partial 'unwinding' after the conserved NPxxY motif around $\mathrm{N} 370^{7.54}$ (Fig. 3), similar to that seen in the structure of the active muscarinic acetylcholine $\mathrm{M} 2$ receptor $^{5}$, but not in the structure of active $\beta_{2} \mathrm{AR}^{7}$. This region (L371-N375) is followed by a short helix 8 (H8) in both NTSR1-LF and NTSR1ELF structures. The aromatic ring of $F 376^{8.50}$, a conserved residue of the H8 motif, is well resolved in NTSR1-LF but is only weakly anchored in a hydrophobic pocket between TM1 and TM7. In NTSR1-ELF, F376 ${ }^{8.50}$ is no longer anchored between TM1 and TM7 but is rotated outward forming hydrophobic interactions with L371. These features of NTSR1-LF and NTSR1-ELF are distinct from the NTSR1 mutant TM86V- $\Delta \mathrm{IC} 3 \mathrm{~A}$, which adopts an apparent inactive receptor conformation at the inner side in the crystal structure, for example, lacking the outward movement of TM6 (ref. 18). In TM86V- $\triangle \mathrm{IC} 3 \mathrm{~A}$, TM7 does not unwind as seen in NTSR1-ELF. The residue F376 $6^{8.50}$ is partially inserted into the pocket between TM1, TM2 and TM7, whereas F376 8.50 of
NTSR1-ELF is not anchored into the receptor core (Fig. 3). In addition, H8 of NTSR1-ELF and NTSR1-LF is shorter than that of TM86V- $\triangle \mathrm{IC} 3 \mathrm{~A}$ by two and three residues from the carboxy (C) terminus, respectively (Supplementary Table 9). Whether this reflects a general instability of $\mathrm{H} 8$ (ref. 18), or its dynamic nature in the active-like receptor conformation, remains to be explored. Recent molecular dynamics simulations suggested that unravelling of $\mathrm{H} 8$ is related to the agonist-occupied state of NTSR1 (ref. 19).

The conserved residue $\mathrm{W} 321^{6.48}$ of the $\mathrm{CWxP}$ motif. Of significance is the position of $\mathrm{W} 321^{6.48}$ within the CWxP motif, a highly conserved amino acid in class A GPCRs. Spectroscopic evidence suggested changes in the environment of $\mathrm{W}^{6.48}$ upon rhodopsin activation ${ }^{20,21}$. However, a rotamer change of $\mathrm{W}^{6.48}$ is not observed in any crystal structure of active rhodopsin ${ }^{22}$, the $\beta_{2} \mathrm{AR}^{6}$ or the M2 receptor ${ }^{5}$ suggesting that changes in the $W^{6.48}$ rotamer orientation might not be an essential part of the GPCR activation mechanism 6 . In contrast to all the previously determined GPCR structures, the W3216.48 side chain in NTSR1-LF and NTSR1-ELF is oriented parallel to the lipid bilayer (Fig. 4; Supplementary Fig. 2). This orientation results from the presence of $F 358^{7.42}$ whose phenyl side chain prevents W $321^{6.48}$ from adopting the side chain conformation found in NTSR1-GW5, which contained the stabilizing F358 $\mathrm{A}^{7.42}$ mutation. Consequently, the W32 $1^{6.48}$ indole side chain makes additional van der Waals interactions with residues of TM3, TM5 and TM6 (Supplementary Fig. 3). It is worth noting that $73 \%$ of 


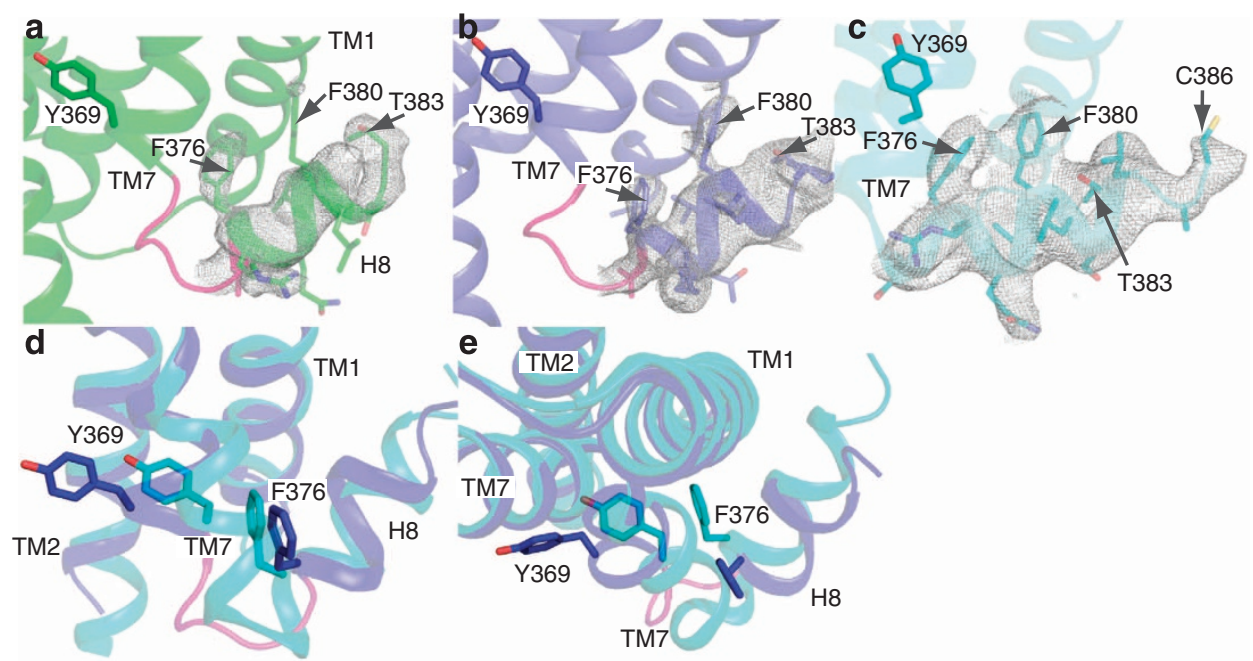

Figure 3 | TM7 and helix 8. (a) NTSR1-LF-T4L is coloured green with mesh outlining the electron density of H8. (b) NTSR1-ELF-T4L in blue. (c) NTSR1 mutant TM86V- $\triangle \mathrm{IC} 3 \mathrm{~A}$ in cyan (PDB code $3 Z \mathrm{EV}^{18}$ ). The partial unwinding of TM7 in NTSR1-ELF-T4L and NTSR1-LF-T4L (indicated by the pink colour) after the conserved $\mathrm{NP}^{7.50} \mathrm{xxY}$ motif allows $\mathrm{F} 376^{8.50}$ to adopt its current position. The aromatic ring of F376 8.50 is weakly anchored between TM1 and TM7 in NTSR1-LF-T4L, but not in NTSR1-ELF-T4L. The 2mFo-DFc sigma-A weighted maps are contoured at 1б. (d,e) Comparison of active-like NTSR1-ELF-T4L (blue) with TM86V- $\triangle \mathrm{IC} 3 \mathrm{~A}$ (cyan). TM3-TM6 have been omitted for clarity.
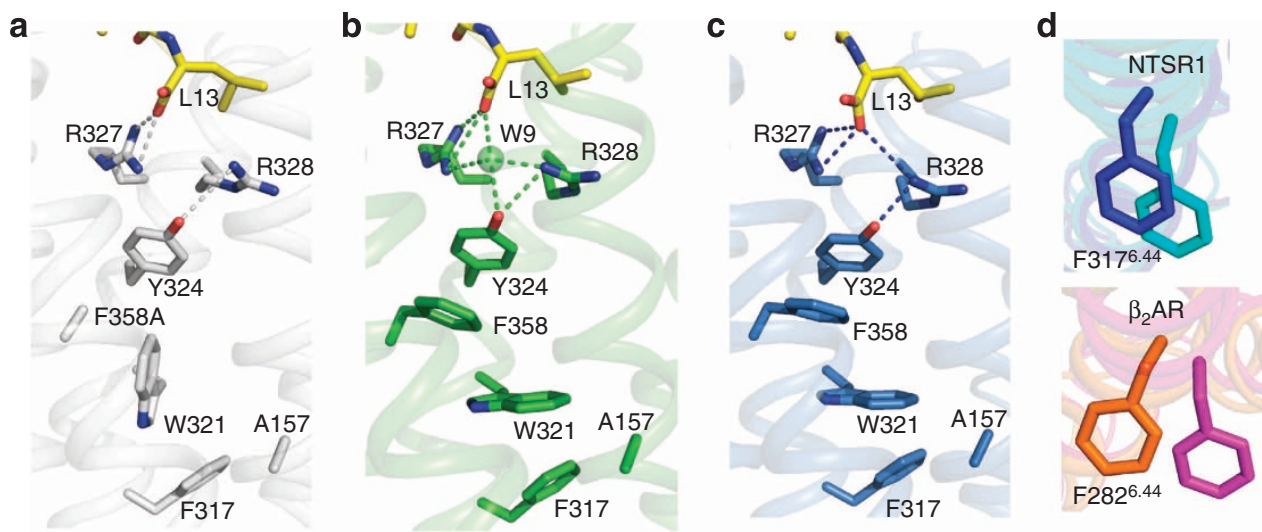

Figure 4 | A hydrogen bond and van der Waals system links the agonist peptide with the hydrophobic core of NTSR1-LF and NTSR1-ELF. NTSR1-GW5T4L (a) (PDB code 4GRV), NTSR1-LF-T4L (b) and NTSR1-ELF-T4L (c) are shown in grey, green and blue, respectively. Individual residues are shown as a stick model and are labelled. L13 of $\mathrm{NTS}_{8-13}$ (yellow) is connected to R327 ${ }^{6.54}, \mathrm{R} 328^{6.55}$ and $\mathrm{Y} 324^{6.51}$ via a hydrogen bond network. Water molecule W9 is labelled. A close-by water molecule W10 that is bonded to L13 of NTS 8 -13 in NTSR1-LF-T4L has been omitted for clarity. No corresponding water molecules were detected in NTSR1-ELF-T4L, likely because of the lower resolution of the structure. A series of stacking interactions relate ${\text { Y } 324^{6.51} \text { to F358 }}^{7.42}$, W321 6.48 and the hydrophobic core ${ }^{23}$ residue F317 ${ }^{6.44}$. (d) Position of the $\mathrm{F}^{6.44}$ side chain in NTSR1-ELF-T4L (blue), the NTSR1 mutant TM86V- $\Delta$ IC3A (cyan, PDB code 3ZEV) and the inactive (purple, PDB code 2RH1) and active $\beta_{2} A R$ (orange, PDB code 3SN6), viewed from the intracellular side.

class A GPCRs, including rhodopsin, have small residues (G, A, S) at position 7.42; bulky tyrosine and phenylalanine residues are rare and comprise only $4 \%$ of class A GPCRs. For example, neuromedin $\mathrm{U}$ receptors and NTSR2 have a phenylalanine at position 7.42 and a tryptophan residue at position 6.48. The luteinizing hormone/choriogonadotropin and thyroidstimulating hormone receptors have a tyrosine at position 7.42, but a methionine at position $6.48 \mathrm{in} \mathrm{lieu}$ of a tryptophan residue. All class A receptors, for which crystal structures have been determined to date, have a small residue at position 7.42 (muscarinic receptors have a cysteine ${ }^{7.42}$ residue, the $\mathrm{P} 2 \mathrm{Y}_{12}$ receptor has a threonine ${ }^{7.42}$ residue, the orexin OX2 receptor has a valine ${ }^{7.42}$ residue) except NTSR1, possibly explaining in part why the $\mathrm{W}^{6.48}$ rotamer conformation seen here in NTSR1-LF and NTSR1-ELF has not been observed in other receptor structures.
A network of interactions links NTS to the hydrophobic core. NTSR1-LF and NTSR1-ELF structures help explain how the agonist peptide transmits its extracellular signal to the intracellular portion of the receptor. Hydrogen bond and van der Waals interactions link $\mathrm{NTS}_{8-13}$ with residues of the hydrophobic core associated with helical rearrangements seen in active-state structure $^{23}$ (Fig. 4). NTS ${ }_{8-13}$ is connected to $Y 324^{6.51}$ via a hydrogen bond network from the carboxylate of its L13 residue through $\mathrm{R} 328^{6.55}$. The aromatic ring of $\mathrm{Y} 324^{6.51}$, in turn, is engaged in hydrophobic stacking interactions with $\mathrm{F} 358^{7.42}$ that is in contact with W $321^{6.48}$, as previously discussed. The hydrophobic network results in the packing of W32 $1^{6.48}$ against the hydrophobic F3176.44 that has been implicated in the reorganization of transmembrane segments upon agonist binding in $\beta_{2} \mathrm{AR}^{6}$. The rotamer position of $\mathrm{F} 317^{6.44}$ is almost the same in NTSR1-GW5, NTSR1-LF and NTSR1-ELF 
(Fig. 4a-c). This is perhaps not surprising as all the three structures represent active-like receptor states (the differences in the ability to activate $G$ protein may, in part, be attributed to the positioning of $\mathrm{R} 167^{3.50}$ by $\mathrm{L} 310^{6.37}$, and the presence of $\mathrm{E} 166^{3.49}$, as discussed). However, comparison of NTSR1-ELF with the mutant TM86V- $\Delta \mathrm{IC} 3 \mathrm{~A}^{18}$, which represents an inactive NTSR 1 at the inner side, suggests a rearrangement of the $\mathrm{F} 317^{6.44}$ side chain (Fig. 4d). The extent of the $\mathrm{F} 317^{6.44}$ repacking upon activation of NTSR1 remains to be determined as F317 ${ }^{6.44}$ in TM86V- $\Delta \mathrm{IC} 3 \mathrm{~A}$ is in a receptor region, which may not represent a fully inactive conformation. The network of hydrophobic interactions identified in NTSR1-LF and NTSR1-ELF were not seen in the NTSR1-GW5 structure owing to the F358A $\mathrm{A}^{7.42}$ stabilizing mutation.

The collapsed $\mathrm{Na}^{+}$ion-binding pocket. $\mathrm{Na}^{+}$ions have a negative allosteric effect on agonist binding to wild-type NTSR1 and the highly conserved D $113^{2.50}$ in the middle of TM2 has been assigned a pivotal role in the $\mathrm{Na}^{+}$ion sensitivity of agonist binding and G-protein activation ${ }^{24}$. Recent high-resolution structures of GPCRs in the inactive state have revealed a conserved $\mathrm{Na}^{+}$ion-binding pocket within the receptor transmembrane bundle ${ }^{25-28}$, providing a structural explanation for the allosteric effect of $\mathrm{Na}^{+}$ions on agonist binding. In each of those inactive structures, the $\mathrm{Na}^{+}$ion is coordinated by a salt bridge to the highly conserved $\mathrm{D}^{2.50}$ and by four additional contacts with receptor side chains and water molecules (Fig. 5d). In the active-like NTSR1-LF and NTSR1-ELF structures (and in NTSR1-GW5), the $\mathrm{Na}^{+}$ion-binding pocket has collapsed (Fig. 5), which explains the reduced $\mathrm{Na}^{+}$ion sensitivity of agonist binding (Supplementary Table 2). The D113 2.50 side chain atoms form an extensive hydrogen bond network with $\mathrm{T} 156^{3.39}, \mathrm{~S} 362^{7.46}$ and $\mathrm{N} 365^{7.49}$ of the NPxxY motif, preventing the coordination of $\mathrm{a} \mathrm{Na}^{+}$ion. Absent in the collapsed NTSR1
$\mathrm{Na}^{+}$ion pocket are any water molecules, which fill the cavity in inactive-state receptors ${ }^{26}$. In NTSR1-LF and NTSR1-ELF, W32 $1^{6.48}$ forms van der Waals interaction with residues of the $\mathrm{Na}^{+}$ion-binding pocket, effectively sealing off the top of the collapsed $\mathrm{Na}^{+}$ion pocket and disrupting a vertical cavity seen in NTSR1-GW5 (Supplementary Fig. 4).

The structure of the NTSR 1 mutant TM86V- $-\mathrm{IC} 3 \mathrm{~A}^{18}$ is similar to our active-like NTSR1 structures in the extracellular half, which is responsible for ligand binding, but dissimilar in the intracellular half, adopting an apparent inactive receptor conformation in the crystal structure. The $\mathrm{Na}^{+}$ion-binding region is located underneath the ligand binding pocket between the intracellular and extracellular receptor halves. In TM86V$\triangle \mathrm{IC} 3 \mathrm{~A}$, the $\mathrm{D} 113^{2.50}$ side chain is also in contact with neighbouring residues, albeit the interactions are different when compared with NTSR1-GW5, NTSR1-LF and NTSR1-ELF (Fig. 5). In addition, no electron density for water molecules or a $\mathrm{Na}^{+}$ion has been reported in the TM86V- $\Delta \mathrm{IC} 3 \mathrm{~A}$ structure ${ }^{18}$. Note that S362 $2^{7.46}$, which contacts D113 2.50 in NTSR1-LF and NTSR1-ELF, is mutated to an alanine residue in TM86V- $\mathrm{IC} 3 \mathrm{~A}$ (Fig. 5).

The residue $L 310^{6.37}$ positions the $R 167^{3.50}$ side chain. The residue at position 6.37 (L310 6.37 in NTSR1) is highly conserved among class A GPCRs; $80 \%$ of receptors have hydrophobic residues $(L, I, V)$ at this position. The significance of this residue becomes apparent in the NTSR1-LF and NTSR1-ELF structures (Fig. 6). L310 6.37 is central to the positioning of the R167 3.50 side chain such as to allow a bona fide productive interaction with the $\mathrm{G}$ protein. In the signalling incompetent, active-like NTSR1-GW5 structure, R167 3.50 is linked to the conserved N257 $7^{5.58}, \mathrm{~S} 164^{3.47}$ and $\mathrm{G} 306^{6.33}$ by a hydrogen bond network, likely facilitated by the decreased side chain size of the $\mathrm{L} 310 \mathrm{~A}^{6.37}$ stabilizing mutation. Those interactions stabilize $\mathrm{R} 167^{3.50}$ in a position

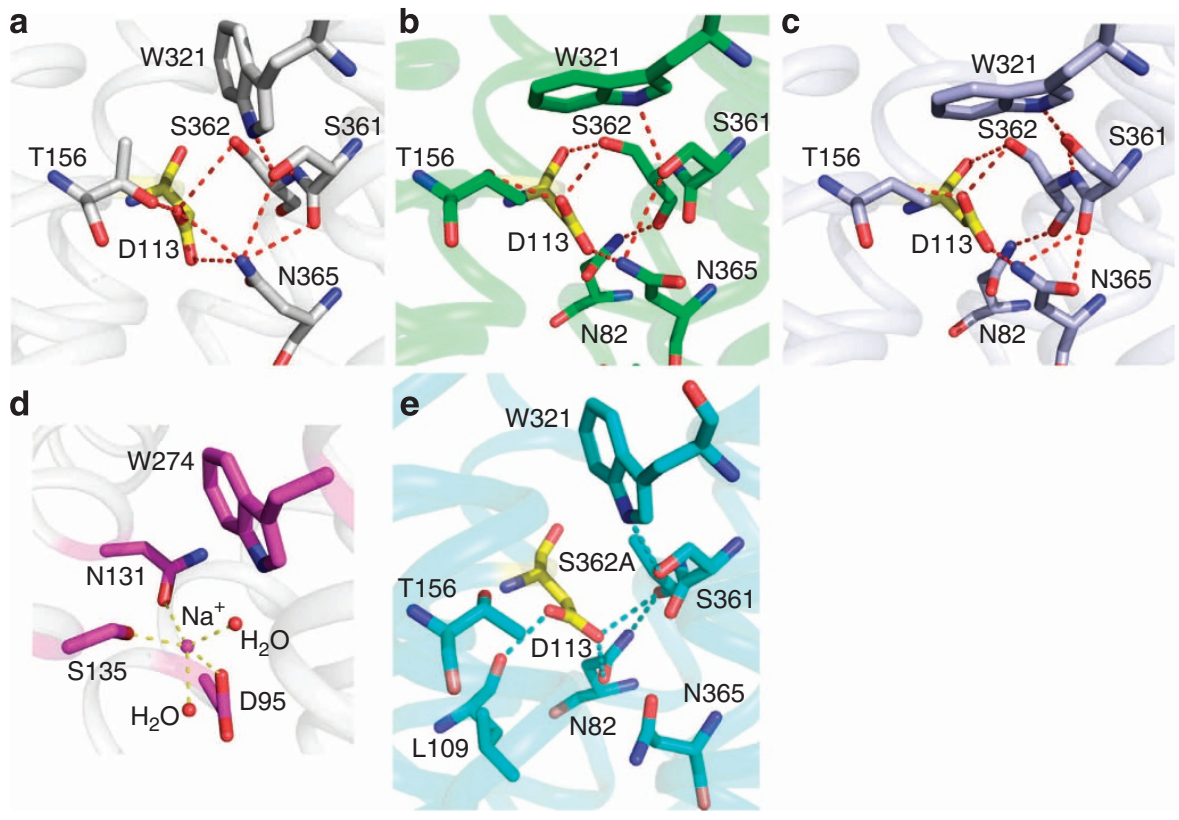

Figure 5 | The collapsed $\mathbf{N a}^{+}$ion-binding pocket. (a) NTSR1-GW5-T4L (grey, PDB code 4GRV), (b) NTSR1-LF-T4L (green), (c) NTSR1-ELF-T4L (blue). The conserved $\mathrm{D} 113^{2.50}$ residue (yellow), which has been assigned a crucial role in the $\mathrm{Na}^{+}$ion sensitivity of agonist binding, engages in hydrogen bond interactions with $\mathrm{T} 156^{3.39}, \mathrm{~S} 362^{7.46}$ and $\mathrm{N} 365^{7.49}$ preventing the coordination of a Na+ ion. Other polar interactions between nearby residues are also shown. Residues of TM5 have been removed from the cartoons for clarity. (d) Inactive $\delta$-opioid receptor (purple, PDB code $4 \mathrm{~N} 6 \mathrm{H}^{25}$ ) with a Na ${ }^{+}$ion coordinated by residues D95 $2.50, \mathrm{~N} 131^{3.35} \mathrm{~S} 135^{3.39}$ and two water molecules. (e) NTSR1 mutant TM86V- $\Delta$ IC3A (cyan, PDB code 3ZEV). Polar interactions are shown as dashed cyan lines. No electron density for water molecules or a $\mathrm{Na}^{+}$ion has been reported ${ }^{18}$. 


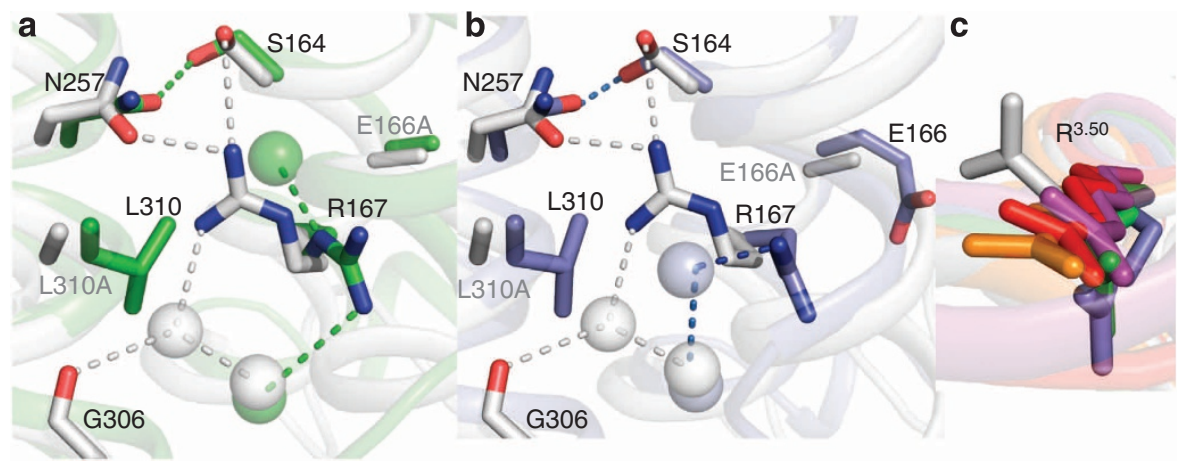

Figure 6 | Effect of $\mathbf{L} 310^{6.37}$ on the positioning of the $\mathbf{R} 167^{\mathbf{3 . 5 0}}$ side chain. (a,b) Comparison of NTSR1-LF-T4L (green) and NTSR1-ELF-T4L (blue) with NTSR1-GW5-T4L (grey, PDB code 4GRV). Hydrogen bonds are indicated by dashed lines, and water molecules are represented as spheres. In NTSR1GW5-T4L, the R167 3.50 side chain is stabilized by a hydrogen bond network to N257 $5.58, \mathrm{~S} 164^{3.47}$ and G306 ${ }^{6.33}$, facilitated by the L310A mutation. The presence of the larger side chain of L310 6.37 in NTSR1-LF-T4L and NTSR1-ELF-T4L is sterically incompatible with such an arrangement and the R1673.50 side chain interactions with $\mathrm{N} 257^{5.58}$ and S164.47 are lost. (c) The R167 side chain now adopts a conformation similar to that seen in metarhodopsin II (ref. 4; purple, PDB code 3PQR), the $\beta_{2} \mathrm{AR}-\mathrm{Gs}$ complex ${ }^{7}$ (orange, PDB code 3SN6) and the active M2 receptor ${ }^{5}$ (red, PDB code 4MQS).

unfavourable for contacting the $\mathrm{G} \alpha$ subunit. The presence of the larger $\mathrm{L} 310^{6.37}$ side chain prevents $\mathrm{R} 167^{3.50}$ from adopting the conformation seen in NTSR1-GW5 (Fig. 6). In NTSR1-LF and NTSR1-ELF, the R167 $7^{3.50}$ side chain has an orientation that is similar to that found in the $\beta_{2} \mathrm{AR}-\mathrm{Gs}$ complex $^{7}$, the active M2 receptor $^{5}$ and opsin in its G-protein-interacting conformation ${ }^{29}$. The current NTSR1 structures represent snapshots of an activelike receptor bound to agonist, but not to a $G$ protein, possibly explaining subtle differences of the R167 $67^{3.50}$ side-chain conformations compared with receptor structures in complex with $\mathrm{G}$ protein or $\mathrm{G}$ protein mimetics (Fig. 6).

\section{Discussion}

Stabilization of detergent-solubilized receptor-ligand complexes is one of the key factors for successful crystallization and structure determination of membrane proteins. Wild-type NTSR1 is not particularly stable in detergent solution ${ }^{30}$; thus the use of stabilized NTSR1 mutants has resulted in the successful production of well-diffracting crystals (Supplementary Table 3). Our previously reported active-like NTSR1-GW5 mutant ${ }^{3}$ was obtained by conformational thermostabilization ${ }^{31}$ in the presence of the agonist neurotensin ${ }^{12,30}$. An alternative approach, directed evolution $^{32-34}$, has resulted in structures of NTSR1 (ref. 18), which are similar to our active-like NTSR1 structures in the extracellular half but have adopted an apparent inactive receptor conformation in the intracellular half.

The structures of NTSR1-LF and NTSR1-ELF, presented here, are very similar (root mean squared deviation values of $0.3 \AA$ for $\mathrm{C} \alpha$ atoms, excluding T4 lysozyme), yet their ability to activate the $\mathrm{G}$ protein in response to NTS differs: NTSR1-LF mediates moderate nucleotide exchange at G $\alpha$, whereas NTSR1-ELF has almost wild-type receptor properties (Supplementary Table 2). The glutamic acid 3.49 of the highly conserved D/ERY motif, absent in NTSR1-LF, but present in NTSR1-ELF, has been deemed critical for G-protein coupling ${ }^{15}$. Thus the mutation E166 $\mathrm{A}^{3.49}$ alone may explain the pharmacological behaviour of NTSR1-LF, highlighting the importance of E166 $6^{3.49}$ for G-protein activation. In the active M2 receptor, D120.49 is stabilized by a hydrogen bond with $\mathrm{N} 58^{2.39}$ (T68 2.39 in $\beta_{2} \mathrm{AR}$ ); and it has been suggested that $\mathrm{N} 58^{2.39}$ either directly stabilizes the active receptor conformation, or engages in direct interactions with $\mathrm{G}$ protein ${ }^{5}$. The equivalent residue in NTSR1 is V102 2.39 precluding side chain hydrogen bond interactions; instead, E166 $6^{3.49}$ is hydrogen bonded to the side chain of $\mathrm{T} 101^{2.38}$, the main chain amide of
$\mathrm{V} 102^{2.39}$, and weakly linked to $\mathrm{H} 105^{2.42}$ (Supplementary Fig. 5). In the $\beta_{2} \mathrm{AR}-\mathrm{Gs}$ complex ${ }^{7}, \mathrm{~T}^{2.39}$ and $\mathrm{D} 130^{3.49}$ interact with the ICL2 helix via Y141 ${ }^{\text {ICL2 }}$ positioning the helix such that a phenylalanine docks into a hydrophobic pocket on the $G$ protein surface. ICL2 has been found essential for the G-protein activation pathway, especially for the dissociation of the receptor- $G$ protein complex in the presence of $\mathrm{GTP}^{35}$. Thus E166 3.49 may optimally position ICL2 in the presence of $G$ protein allowing efficient G-protein binding and release. In $\beta_{2} \mathrm{AR}$, Y141 ${ }^{\text {ICL2 }}$ links the receptor-G protein interactions of ICL2 with the D/ERY motif. The equivalent interaction in NTSR1 may come by $\mathrm{M} 181^{\mathrm{ICL} 2}$ as the NTSR1 residue, equivalent to Y141 ${ }^{\text {ICL2 }}$ of $\beta_{2} \mathrm{AR}$, is an alanine (A177).

In conclusion, our current NTSR1 structures provide insight into mechanistic details of an active-like, agonist-occupied peptide GPCR. The conserved $\mathrm{W} 321^{6.48}$, oriented parallel to the membrane plane, seals the top of a collapsed $\mathrm{Na}^{+}$ion-binding pocket; W32 $1^{6.48}$ in combination with F358 ${ }^{7.42}$ link the agonist peptide, bound near the receptor surface, with hydrophobic core residues in the inner half of NTSR1. The highly conserved residue $\mathrm{L} 310^{6.37}$ in the vicinity of the D/ERY motif is central to the sidechain orientation of $\mathrm{R} 167^{3.50}$ to promote the productive interaction with $\mathrm{Gq}$ protein. The neighbouring E166 ${ }^{3.49}$ residue is vital for G-protein activation, possibly by coupling receptor-G protein interactions with the D/ERY motif.

\section{Methods}

NTSR1 constructs. The baculovirus construct NTSR1-LF-T4L consisted of the hemagglutinin signal peptide and the Flag tag ${ }^{36}$, followed by the thermostabilized rat NTSR1 (T43-K396 containing the mutations A86L, E166A, G215A, V360A) with the ICL3 residues H269-E296 replaced by the cysteine-free bacteriophage T4 lysozyme (N2-Y161 with the mutations C54T and C97A) and a GSGS linker. A deca-histidine tag was placed at the $C$ terminus. NTSR1-LF contained the wild-type ICL3 sequence. NTSR1-ELF-T4L and NTSR1-ELF were like NTSR1-LF-T4L and NTSR1-LF, respectively, but had only three mutations (A86L, G215A, V360A). The wild-type NTSR1 used here was like NTSR1-LF but did not have the four mutations. Additional NTSR1 mutants, used for pharmacological analyses, are listed in Supplementary Table 1.

In the Methods sections, we distinguish between NTSR1 constructs containing T4L or the wild-type ICL3 sequence. In the main text, we use only one name for a particular construct; for example, NTSR1-ELF refers interchangeably to NTSR1ELF-T4L and NTSR1-ELF, the latter containing the wild-type ICL3, not T4L. The identity of the respective construct is evident from the context of writing.

Expression of NTSR1 in insect cells. Recombinant baculoviruses were generated using a modified pFastBacl transfer plasmid (Invitrogen). Trichoplusia ni cells were infected with recombinant virus, and the temperature was lowered from 27 to $21^{\circ} \mathrm{C}$. Cells were collected by centrifugation $48 \mathrm{~h}$ post infection, resuspended in 
hypotonic buffer (10 $\mathrm{mM}$ Hepes $\left.\mathrm{pH} 7.5,10 \mathrm{mM} \mathrm{MgCl}_{2}, 20 \mathrm{mM} \mathrm{KCl}\right)$, flash frozen in liquid nitrogen and stored at $-80^{\circ} \mathrm{C}$ until use.

Expression of Gq protein in insect cells. The baculovirus construct His-Tev-G $\propto \mathrm{q}$ consisted of a hexa-histidine tag, followed by a tobacco etch virus (TEV) protease recognition site and the human $\mathrm{G} \alpha \mathrm{q}$ sequence (M7-V359). Human G $\beta_{1}$ was unmodified. Human $\mathrm{G} \gamma_{1}$ was preceded by a hexa-histidine tag. We refer to His-Tev-G $\alpha q$ G $\beta_{1}$ His-G $\gamma_{1}$ as Gq protein. Trichoplusia ni cells were triple-infected with the recombinant viruses at $27^{\circ} \mathrm{C}$. Cells were collected by centrifugation $48 \mathrm{~h}$ post infection, resuspended in hypotonic buffer $(10 \mathrm{mM}$ Hepes $\mathrm{pH} 7.5,10 \mathrm{mM}$ $\mathrm{MgCl}_{2}, 20 \mathrm{mM} \mathrm{KCl}$ ), flash frozen in liquid nitrogen and stored at $-80^{\circ} \mathrm{C}$ until use.

\section{Preparation of urea-washed P2 insect cell membranes. NTSR1-enriched} membranes were obtained as a P2 fraction from insect cells ${ }^{30,37}$. Before G-proteincoupling assays and ligand binding experiments, the P2 membranes were treated with urea to remove peripherally bound membrane proteins ${ }^{38,39}$. The receptor density in urea-washed P2 membranes was determined by $\left[{ }^{3} \mathrm{H}\right] \mathrm{NTS}$ saturation binding analysis ${ }^{30}$

Ligand-binding experiments. All radioligand binding assays were conducted with urea-washed P2 insect cell membranes containing the indicated NTSR1 constructs. Independent experiments were carried out in single data points.

For agonist $\left[{ }^{3} \mathrm{H}\right] \mathrm{NTS}([3,11-$ tyrosyl-3,5-3H(N)]-pyroGlu-Leu-Tyr-Glu-AsnLys-Pro-Arg-Arg-Pro-Tyr-Ile-Leu; PerkinElmer) saturation binding experiments, receptors were incubated on ice for $1 \mathrm{~h}$ in $250 \mu \mathrm{l}$ TEBB buffer $(50 \mathrm{mM}$ TrisHCl pH 7.4, $1 \mathrm{mM}$ ethylenediaminetetraacetic acid (EDTA), $40 \mu \mathrm{g} \mathrm{ml}^{-1}$ bacitracin, $0.1 \%$ $(\mathrm{w} / \mathrm{v}) \mathrm{BSA})$ containing $\left[{ }^{3} \mathrm{H}\right] \mathrm{NTS}$ at a concentration of $0.6-20 \mathrm{nM}$. Nonspecific $\left[{ }^{3} \mathrm{H}\right] \mathrm{NTS}$ binding was determined in the presence of $50 \mu \mathrm{M}$ unlabelled NTS. Separation of bound from free ligand was achieved by rapid filtration through $\mathrm{GF} / \mathrm{B}$ glass fibre filters (Whatman) pretreated with polyethylenimine $(0.5 \% \mathrm{w} / \mathrm{v})$ The amount of radioactivity was quantified by liquid scintillation counting (Beckman LS 6500). Data were analysed by nonlinear regression using the GraphPad Prism software and best fit to a one-site binding equation to determine the dissociation constants $\left(\mathrm{K}_{\mathrm{d}}\right)$. Note that the saturation binding experiments using wild-type NTSR1 were conducted at equilibrium. In contrast, binding of $\left[{ }^{3} \mathrm{H}\right] \mathrm{NTS}$ to the NTSR1 mutants did not reach equilibrium within the incubation time because of the slow agonist off-rates (discussed previously).

Homologous competition assays with NTS were performed in the presence of $\left[{ }^{3} \mathrm{H}\right] \mathrm{NTS}$ (TEBB buffer, $4.5-5 \mathrm{nM}\left[{ }^{3} \mathrm{H}\right] \mathrm{NTS}$, NTSR1 concentration $<0.5 \mathrm{nM}$, incubation for $2 \mathrm{~h}$ on ice, $250 \mu \mathrm{l}$ assay volume). Data were best fit to a sigmoidal dose-response equation with standard slope using the concentrations of total NTS added versus bound $\left[{ }^{3} \mathrm{H}\right] \mathrm{NTS}$. Inhibition constant $\left(\mathrm{K}_{\mathrm{i}}\right)$ values were derived from $\mathrm{IC}_{50}$ values using the Cheng and Prusoff equation, $\mathrm{K}_{\mathrm{i}}=\mathrm{IC}_{50} /\left(1+\mathrm{L} / \mathrm{K}_{\mathrm{d}}\right)$, where $\mathrm{L}$ is the concentration of $\left[{ }^{3} \mathrm{H}\right]$ NTS (ref. 40 ).

Competition assays with the nonpeptide antagonist SR48692 (ref. 14) were performed in the presence of $\left[{ }^{3} \mathrm{H}\right]$ NTS (TEBB buffer, $5 \mathrm{nM}\left[{ }^{3} \mathrm{H}\right] \mathrm{NTS}$, NTSR 1 concentration $<0.5 \mathrm{nM}$, incubation for $2 \mathrm{~h}$ on ice, $250 \mu \mathrm{l}$ assay volume). Data were analysed by nonlinear regression with the GraphPad Prism three-parameter doseresponse equation (standard slope) using the concentrations of total SR48692 added versus bound $\left[{ }^{3} \mathrm{H}\right] \mathrm{NTS}$.

The effect of $\mathrm{Na}^{+}$ions on $\left[{ }^{3} \mathrm{H}\right] \mathrm{NTS}$ binding was measured with $\mathrm{NaCl}$ concentrations ranging from 0 to $2 \mathrm{M}$ (TEBB buffer, $8 \mathrm{nM}\left[{ }^{3} \mathrm{H}\right] \mathrm{NTS}$, NTSR 1 concentration $<0.5 \mathrm{nM}$, incubation for $1.5 \mathrm{~h}$ on ice, $300 \mu \mathrm{l}$ assay volume). Data were analysed by nonlinear regression using the GraphPad Prism four-parameter dose-response equation (variable slope) with the top and bottom plateaux constrained from $100 \%$ to $10 \%$ (wild-type NTSR1) and $100 \%$ to $50 \%$ (NTSR1-LFT4L, NTSR1-LF, NTSR1-ELF-T4L, NTSR1-ELF), respectively.

The association of $\left[{ }^{3} \mathrm{H}\right] \mathrm{NTS}$ was assessed at a concentration of $10 \mathrm{nM}$ (TEBB buffer, NTSR1 concentration $<0.5 \mathrm{nM}$ ). At the indicated time points, $250 \mu \mathrm{l}$ aliquots were filtered over glass fibre filters. After $2 \mathrm{~h},\left[{ }^{3} \mathrm{H}\right] \mathrm{NTS}$ dissociation was initiated by adding $41.7 \mu \mathrm{M}$ unlabelled NTS or by the addition of $41.7 \mu \mathrm{M}$ NTS and $833 \mathrm{mM} \mathrm{NaCl}$; this step reduced the concentration of $\left[{ }^{3} \mathrm{H}\right] \mathrm{NTS}$ to $8 \mathrm{nM}$. The samples were subjected to filtration after the indicated time points. No attempt was made to quantitatively compare the observed rates of association and the dissociation rate constants between NTSR1 constructs because of the very fast association of agonist to wild-type NTSR1 (ref. 3), the very fast dissociation of agonist from wild-type NTSR1 in the presence of $\mathrm{NaCl}$ (ref. 3) and the slow dissociation of $\left[{ }^{3} \mathrm{H}\right]$ NTS from the NTSR1 mutants.

GTP $\gamma \mathbf{S}$ assays. Before G-protein-coupling assays, the P2 membranes were treated with urea to remove peripherally bound membrane protein $s^{38,39}$. GDP/ $\left./{ }^{35} \mathrm{~S}\right] \mathrm{GTP} \gamma \mathrm{S}$ exchange assays were performed ${ }^{30,41}$ with $1 \mathrm{nM}$ receptor, $140 \mathrm{nM}$ Gq protein and specified amounts of NTS, nonpeptide antagonist SR48692 (ref. 14) or no ligand in the reaction. Experiments were conducted either at saturating ligand concentrations (NTS at $20 \mu \mathrm{M}$, SR48692 at $40 \mu \mathrm{M}$ ) or using a range of ligand concentrations for dose-response assays ( $0-20 \mu \mathrm{M}$ NTS, $0-40 \mu \mathrm{M}$ SR48692). Independent experiments were carried out in single data points. Urea-washed membranes containing NTSR1 were added to Gq protein and ligand to give a volume of $30 \mu \mathrm{l}$. GDP/GTP $\gamma$ S exchange was initiated by the addition of $20 \mu \mathrm{l}$ of $\left[{ }^{35} \mathrm{~S}\right] \mathrm{GTP} \gamma \mathrm{S}$ mix $\left(5 \mathrm{~min}\right.$ at $\left.30^{\circ} \mathrm{C}\right)$. The final component concentrations in each sample were $50 \mathrm{mM}$ MOPS (3-(N-morpholino)propanesulfonic acid) ( $\mathrm{pH} 7.5$ ), $1 \mathrm{mM}$ EDTA, $120 \mathrm{mM} \mathrm{NaCl}, 1 \mathrm{mM}$ dithiothreitol (DTT), $3 \mathrm{mM} \mathrm{MgSO}_{4}, 0.3 \%$ (w/v) BSA, $1 \mu \mathrm{M}$ GDP, $4-8 \mathrm{nM}\left[{ }^{35} \mathrm{~S}\right] \mathrm{GTP} \gamma \mathrm{S}$ (PerkinElmer), $40 \mu \mathrm{M}$ adenylyl imidodiphosphate, $0.4 \mathrm{mM}$ cytidine $5^{\prime}$-monophosphate, $0.1 \%(\mathrm{w} / \mathrm{v}) 3$-[(3cholamidopropyl)dimethylammonio]propanesulfonic acid (CHAPS; Anatrace). Reactions were terminated by diluting the reaction mixture with $2 \mathrm{ml}$ of ice-cold stop buffer $\left(20 \mathrm{mM}\right.$ TrisHCl pH 8.0, $100 \mathrm{mM} \mathrm{NaCl}$ and $\left.25 \mathrm{mM} \mathrm{MgCl}_{2}\right)$ and were filtered over nitrocellulose membranes on a vacuum manifold. Filters were then washed six times with $2 \mathrm{ml}$ of ice-cold stop buffer. The nitrocellulose membranes were dried, and the radioactivity was quantified by liquid scintillation in a Beckman Coulter LS 6500 scintillation counter. Data from dose-response experiments were fit to equations with a Hill slope of 1 or variable slope.

The Gq protein used for exchange assays was purified in buffer containing CHAPS. However, the Gq protein addition in the exchange assays did not exceed one-fifth of the reaction volume, thus limiting the free CHAPS concentration to one-fourth of its critical micellar concentration ${ }^{42}$

The quantification of purified Gq protein was done as above with the following modifications. Duplicate reaction mixes (final volume of $75 \mu \mathrm{l}$ ) contained $1 \mu \mathrm{M}$ unlabelled GTP $\gamma \mathrm{S}$ instead of GDP, $25 \mathrm{nM}$ receptor, a defined amount of the Gq protein preparation and $10 \mu \mathrm{M}$ NTS or no ligand. Aliquots $(10 \mu \mathrm{l})$ of the reaction mixes were transferred into $2 \mathrm{ml}$ of ice-cold stop buffer after 5, 10, 20 and $30 \mathrm{~min}$ $\left.{ }^{35} \mathrm{~S}\right] \mathrm{GTP} \gamma \mathrm{S}$ binding in the absence of NTS (non-catalysed nucleotide exchange) was subtracted from $\left[{ }^{35} \mathrm{~S}\right] \mathrm{GTP} \gamma \mathrm{S}$ binding in the presence of NTS (total nucleotide exchange). The resulting data were fit to a one-site binding model in the Prism software (GraphPad) to calculate the concentration of His-Tev-G $\alpha \mathrm{q}$.

Purification of Gq protein from insect cells. All the steps were performed at $4{ }^{\circ} \mathrm{C}$ or on ice. Cells from 2 to $4 \mathrm{l}$ of insect cell culture were thawed and sedimented by centrifugation (45Ti rotor, $125,000 \mathrm{~g}, 25 \mathrm{~min}, 4^{\circ} \mathrm{C}$, Optima L90K, Beckman). The pellet was resuspended in buffer using a glass (dounce) tissue grinder with tight pestle. After drop-wise addition of a 10\% (w/v) CHAPS solution, the sample was stirred for $1.5-2 \mathrm{~h}$. The final volume was $50 \mathrm{ml}$ per liter of cell culture, containing $20 \mathrm{mM}$ Hepes pH 8.0, $300 \mathrm{mM} \mathrm{NaCl}, 5 \mathrm{mM} \mathrm{MgCl}_{2}, 5 \mathrm{mM} \beta$-mercaptoethanol, $10 \mu \mathrm{M}$ GDP, $100 \mu \mathrm{M}$ AEBSF (4-(2-Aminoethyl)benzene sulfonyl fluoride hydrochloride), $3 \mu \mathrm{g} \mathrm{ml}^{-1}$ leupeptin, $3 \mu \mathrm{g} \mathrm{ml}^{-1}$ trypsin inhibitor, $20 \mu \mathrm{g} \mathrm{ml}^{-1}$ tosyl lysyl chloromethyl ketone, $20 \mu \mathrm{g} \mathrm{ml}^{-1}$ tosyl phenylalanyl chloromethyl ketone, $50 \mathrm{~g} \mathrm{ml}^{-1}$ deoxyribonuclease, $1 \%$ (w/v) CHAPS. The sample was clarified by centrifugation (45Ti rotor, $125,000 \mathrm{~g}, 1 \mathrm{~h}$, Optima L90K, Beckman), diluted 1.5-fold with detergent-free buffer to reduce the CHAPS concentration to $0.67 \%(\mathrm{w} / \mathrm{v})$, adjusted with imidazole to a final concentration of $50 \mathrm{mM}$, and batch-incubated overnight with Ni-NTA resin (1 $\mathrm{ml}$ resin per liter of cell culture) equilibrated with buffer GA (20 mM Hepes pH 8.0, $300 \mathrm{mM} \mathrm{NaCl}, 5 \mathrm{mM} \mathrm{MgCl}$, $5 \mathrm{mM} \beta$-mercaptoethanol, $10 \mu \mathrm{M}$ GDP, $50 \mathrm{mM}$ imidazole, $0.5 \%$ (w/v) CHAPS). After washing the resin with 15 column volumes of buffer $\mathrm{GA}$, the $\mathrm{G}$ protein was eluted with buffer GB (20 mM Hepes pH 8.0, $300 \mathrm{mM} \mathrm{NaCl}, 5 \mathrm{mM} \mathrm{MgCl}_{2}, 5 \mathrm{mM} \beta$-mercaptoethanol, $250 \mathrm{mM}$ imidazole, $0.5 \%$ (w/v) CHAPS).

For some Gq protein preparations, the sample was subjected to ion exchange chromatography before the final size exclusion chromatography step. For this, protein containing Ni-NTA fractions were pooled, supplemented with $10 \mu \mathrm{M}$ GDP concentrated using a 30,000 MWCO concentrator (Amicon Ultra, Millipore) and passed over PD10 columns (GE Healthcare) equilibrated in IEX binding buffer (20 mM Hepes pH 8.0, $5 \mathrm{mM} \mathrm{MgCl}, 1 \mathrm{mM}$ DTT, $0.5 \%$ (w/v) CHAPS) supplemented with $10 \mu \mathrm{M}$ GDP. Then the sample was concentrated and loaded onto a $1 \mathrm{ml}$ HiTrap DEAE FF column (GE Healthcare) equilibrated in IEX binding buffer. After washing with IEX binding buffer, the Gq protein was eluted using a gradient to $100 \%$ elution buffer (20 mM Hepes $\mathrm{pH} 8.0,5 \mathrm{mM} \mathrm{MgCl}_{2}, 1 \mathrm{mM}$ DTT, $500 \mathrm{mM} \mathrm{NaCl}, 0.5 \%$ (w/v) CHAPS) over 10 column volumes.

Finally, the protein containing Ni-NTA or IEX fractions were pooled and supplemented with $10 \mu \mathrm{M}$ GDP, concentrated using a 30,000 MWCO concentrator (Amicon Ultra, Millipore) and run on a Superose 6 10/300 column (GE Healthcare) equilibrated in GF buffer (10 mM MOPS pH 7.5, $100 \mathrm{mM} \mathrm{NaCl}, 1 \mathrm{mM}$ DTT, $0.5 \%(w / v)$ CHAPS). The fractions containing Gq protein were pooled, supplemented with $10 \mu \mathrm{M} \mathrm{GDP}$, aliquoted, flash frozen and stored at $-80^{\circ} \mathrm{C}$ until use for pharmacological experiments.

Purification of NTSR1-LF-T4L and NTSR1-ELF-T4L. The cells from 31 of insect cell culture were thawed and the volume was brought to $\sim 240 \mathrm{ml}$ with hypotonic buffer $(10 \mathrm{mM}$ Hepes pH 7.5, $10 \mathrm{mM} \mathrm{MgCl}, 20 \mathrm{mM} \mathrm{KCl})$. The cells were then resuspended using a Turrax T-25 (IKA) homogenizer at 8,000 r.p.m. for 2 min. After centrifugation (45Ti rotor, 125,000 g, $20 \mathrm{~min}, 4^{\circ} \mathrm{C}$, Optima L90K, Beckman), the membranes were resuspended (Turrax T-25) in $\sim 180 \mathrm{ml}$ of high-salt buffer (10 mM Hepes pH 7.5, $1 \mathrm{M} \mathrm{NaCl}, 10 \mathrm{mM} \mathrm{MgCl}, 20 \mathrm{mM} \mathrm{KCl}$ ) supplemented with AEBSF $(100 \mu \mathrm{M})$ and centrifuged again. The high-salt buffer wash was repeated one more time resulting in $\sim 12 \mathrm{~g}$ of wet membrane pellet. All the subsequent steps were performed at $4{ }^{\circ} \mathrm{C}$ or on ice, and AEBSF $(100 \mu \mathrm{M}$ final concentration) was repeatedly added throughout the procedure. The washed membranes were resuspended in $122 \mathrm{ml}$ of buffer $(80 \mathrm{mM}$ TrisHCl pH 7.4, 48\% (v/v) glycerol) containing $16 \mu \mathrm{M} \mathrm{NTS}_{8-13}$ (Arg-Arg-Pro-Tyr-Ile-Leu) and stirred for $45 \mathrm{~min}$ to allow agonist binding to membrane-inserted NTSR1. The receptor was extracted by drop-wise 
addition of $65 \mathrm{ml}$ of a $3 \%(\mathrm{w} / \mathrm{v})$ lauryl maltose neopentyl glycol (2,2-didecylpropane-1,3-bis- $\beta$-D-maltopyranoside; LMNG; Anatrace ${ }^{43} / 0.3 \%$ (w/v) CHS

(cholesteryl hemisuccinate Tris salt) solution (Anatrace). After $1 \mathrm{~h}, \mathrm{NaCl}$ was added and the solution was gently stirred for an additional $15 \mathrm{~min}$. The final volume was $195 \mathrm{ml}$ containing $50 \mathrm{mM}$ TrisHCl pH 7.4, 30\% (v/v) glycerol, $200 \mathrm{mM} \mathrm{NaCl}, 1 \%$ $(\mathrm{w} / \mathrm{v}) \mathrm{LMNG} / 0.1 \%(\mathrm{w} / \mathrm{v}) \mathrm{CHS}$ and $10 \mu \mathrm{M} \mathrm{NTS}_{8-13}$. The sample was clarified by centrifugation (45Ti rotor, 125,000g, $1 \mathrm{~h}$, Optima L90K, Beckman), adjusted with imidazole to a final concentration of $20 \mathrm{mM}$ and batch-incubated overnight with $1.5 \mathrm{ml}$ Talon resin equilibrated with Talon- $\mathrm{A}^{+}$buffer $(50 \mathrm{mM}$ TrisHCl $\mathrm{pH} 7.4$, $30 \%(\mathrm{v} / \mathrm{v})$ glycerol, $200 \mathrm{mM} \mathrm{NaCl}, 20 \mathrm{mM}$ imidazole, $1 \mu \mathrm{M} \mathrm{NTS}_{8-13}, 0.1 \%(\mathrm{w} / \mathrm{v})$ LMNG/0.01\% (w/v) CHS). After washing the resin with $22.5 \mathrm{ml}$ of buffer Talon$\mathrm{A}^{+}$and $15 \mathrm{ml}$ of buffer Talon-A2 ${ }^{+}(50 \mathrm{mM}$ TrisHCl pH 7.4, 30\% (v/v) glycerol, $200 \mathrm{mM} \mathrm{NaCl}, 20 \mathrm{mM}$ imidazole, $1 \mu \mathrm{M} \mathrm{NTS}_{8-13}, 0.05 \%$ (w/v) LMNG/0.005\% (w/v) CHS), NTSR1-LF-T4L and NTSR1-ELF-T4L were eluted in $0.5 \mathrm{ml}$ steps with Talon-B ${ }^{+}$buffer $(50 \mathrm{mM}$ TrisHCl pH 7.4, 30\% (v/v) glycerol, $200 \mathrm{mM} \mathrm{NaCl}$, $250 \mathrm{mM}$ imidazole, $10 \mu \mathrm{M} \mathrm{NTS}_{8-13}, 0.05 \%$ (w/v) LMNG/0.005\% (w/v) CHS). Peak fractions were collected $(2.5 \mathrm{ml})$ and desalted using a PD10 column equilibrated in PD10 buffer (50 mM TrisHCl pH 7.4, $200 \mathrm{mM} \mathrm{NaCl}, 0.003 \%$ (w/v) LMNG/ $0.0003 \%(\mathrm{w} / \mathrm{v}) \mathrm{CHS})$. NTS $\mathrm{NT}_{8-13}$ was then added to a concentration of $20 \mu \mathrm{M}$, and the sample was used for crystallization. Three litres of insect cell culture yielded $\sim 2 \mathrm{mg}$ of purified NTSR1-LF-T4L or NTSR1-ELF-T4L.

Stability tests in detergent solution. The cell pellets from $10 \mathrm{ml}$ of insect cell cultures were resuspended in $1.8 \mathrm{ml}$ buffer containing LMNG/CHS to give a final buffer composition of $50 \mathrm{mM}$ TrisHCl pH 7.4, $200 \mathrm{mM} \mathrm{NaCl}, 1 \%$ (w/v) LMNG/ $0.1 \%(\mathrm{w} / \mathrm{v}) \mathrm{CHS}$. The samples were placed on a rotating mixer at $4{ }^{\circ} \mathrm{C}$ for $1 \mathrm{~h}$. Cell debris and non-solubilized material were removed by ultracentrifugation (TLA 120.2 rotor, $128,000 \mathrm{~g}, 4^{\circ} \mathrm{C}, 30 \mathrm{~min}$ in Optima Max bench-top ultracentrifuge, Beckman) and the supernatants containing detergent-solubilized NTSR1 were used to test for thermal stability in the + NTS format ${ }^{30}$. For thermal denaturation curves, the supernatants were diluted 6.67-fold into assay buffer $(50 \mathrm{mM}$ TrisHCl $\mathrm{pH} 7.4,200 \mathrm{mM} \mathrm{NaCl}$ ) containing $10 \mathrm{nM}\left[{ }^{3} \mathrm{H}\right] \mathrm{NTS}$ and incubated for $1-2.5 \mathrm{~h}$ on ice to allow $\left[{ }^{3} \mathrm{H}\right] \mathrm{NTS}$ binding to NTSR1. The samples ( $120 \mu \mathrm{l}$ aliquots) were exposed to different temperatures between 0 and $70^{\circ} \mathrm{C}$ for $30 \mathrm{~min}$ and placed on ice. Separation of receptor-ligand complex from free ligand $(100 \mu \mathrm{l})$ was achieved by centrifugation-assisted gel filtration (spin assay) using Bio-Spin 30 Tris columns (Bio-Rad), equilibrated with RDB buffer (50 mM TrisHCl pH 7.4, $1 \mathrm{mM}$ EDTA, $0.1 \%(\mathrm{w} / \mathrm{v}) \mathrm{DDM}$ (n-dodecyl- $\beta$-D-maltopyranoside) (Anatrace), $0.2 \%(\mathrm{w} / \mathrm{v})$ CHAPS, $0.04 \%(\mathrm{w} / \mathrm{v}) \mathrm{CHS}$ ). Control reactions on ice were recorded at the start and at the end of each denaturation experiment. The percentage of activity remaining after heat exposure was determined with respect to the unheated control. Data were analysed by nonlinear regression using a Boltzmann sigmoidal equation in the Prism software (GraphPad).

Crystallization. Purified desalted NTSR1-LF-T4L and NTSR1-ELF-T4L were adjusted to $100 \mu \mathrm{M}$ Tris (2-carboxyethyl) phosphine hydrochloride (TCEP) and $350 \mu \mathrm{M} \mathrm{NTS}{ }_{8-13}$ and concentrated to an estimated $30 \mathrm{mg} \mathrm{ml}^{-1}$ using a 100,000 MWCO concentrator (Amicon Ultra, Millipore). After the addition of $\mathrm{NTS}_{8-13}$ to $1.5 \mathrm{mM}$ and centrifugation (TLA 120.1 rotor, $128,000 \mathrm{~g}, 30 \mathrm{~min}, 4^{\circ} \mathrm{C}$, Beckman), the sample was mixed with 1.5 parts by weight of a mix of monoolein with cholesterol $(10: 1)$ using the two-syringe method ${ }^{44}$. The resulting lipidic cubic phase ${ }^{45}$ mix was dispensed in 65-75 $\mathrm{nl}$ drops onto Laminex plates (Molecular Dimensions) and overlaid with $750 \mathrm{nl}$ (NTSR1-LF-T4L) or $875 \mathrm{nl}$ (NTSR1-ELF-T4L) precipitant solution using a Mosquito LCP robot (TTP Labtech). Crystals of NTSR1-LF-T4L grew at $20^{\circ} \mathrm{C}$ after 3 days in precipitant solution consisting of $19.8-23.4 \%(\mathrm{v} / \mathrm{v})$ PEG 400, $80 \mathrm{mM}$ Hepes pH 7.0-7.4, $2 \mathrm{mM}$ TCEP and $50 \mathrm{mM}$ lithium citrate. Crystals of NTSR1-ELF-T4L grew in precipitant solution consisting of 16-24\% (v/v) PEG 400, $75 \mathrm{mM}$ Hepes $\mathrm{pH}$ 7.0-8.0, $1.7 \mathrm{mM}$ TCEP, $32 \mathrm{mM}$ lithium citrate and $0.9 \mathrm{mM} \mathrm{NTS}_{8-13}$. Crystals were harvested directly from LCP using micro-loops (MiTeGen) and immediately flash frozen in liquid nitrogen without adding extra cryoprotectant.

Data collection and structure determination. Data collection was performed using the JBluIce-EPICS data acquisition software at the GM/CA-CAT (23-ID-D) beamline at the Advanced Photon Source of the Argonne National Laboratory using a $10-20 \mu \mathrm{m}$ minibeam at a wavelength of $1.0332 \AA$ and a Pilatus $36 \mathrm{M}$ detector. Crystals within the loops were located by diffraction using the automated rastering module of JBluIce-EPICS ${ }^{46,47}$. Partial data sets (wedges of $20-30$ degrees) were collected from crystals exposed to the non-attenuated minibeam for $0.3 \mathrm{~s}$ and 0.3-degree oscillation per exposure.

For NTSR1-LF-T4L, a 99.4\% complete data set at $2.6 \AA$ resolution was obtained by indexing, integrating, scaling and merging partial data sets from six crystals using $\mathrm{XDS}^{48}$ and Aimless 49 of the CCP4 Suite ${ }^{50}$. For NTSR1-ELF-T4L, a $90.2 \%$ complete data set at $2.9 \AA$ resolution was obtained from partial data sets from five crystals.

Structure determination was performed by molecular replacement using the Phaser module of the CCP4 Suite. Two search models were created using the structure of NTSR1-GW5-T4L $\mathrm{L}^{3}$ (PDB code 4GRV) with one containing the T4 lysozyme domain and one containing the receptor seven-helix bundle. One copy of each search model was found, producing a single solution. Subsequent refinement was performed using the MR solution with rounds of PHENIX.AutoBuild ${ }^{51}$ followed by PHENIX.Refine with simulated annealing, and Refmac5 using translation, libration and screw-rotation (TLS) parameters ${ }^{52}$. TLS displacement groups used in the refinement were defined by the TLSMD server ${ }^{53}$. Manual examination and rebuilding of refined coordinates was accomplished using $\mathrm{COOT}^{54}$. The structures were refined with final $R / R_{\text {free }}$ values of $0.23 / 0.28$ for both NTSR1-LF-T4L and NTSR1-ELF-T4L. The quality of the model was checked using the Molprobity server ${ }^{55}$. The Ramachandran statistics for NTSR1-LF-T4L are: 95.3\% favoured regions, $4.7 \%$ allowed regions, $0 \%$ outliers. The Ramachandran statistics for NTSR1-ELF-T4L are: $94.4 \%$ favoured regions, 5.6\% allowed regions, $0 \%$ outliers. The signal-to-noise ratio of $I / \sigma(I) \geq 2.0$ was at 2.8 and $3.1 \AA$ for NTSR1-LF-T4L and NTSR1-ELF-T4L, respectively. A summary of data collection and refinement statistics is reported in Table 1. Simulated annealing omit maps for H8 were generated using the Composite Omit Map function of the Phenix program suite (Supplementary Fig. 6). A stereo figure of representative electron density for TM7 of NTSR1-LF-T4L and NTSR1-ELF-T4L is given in Supplementary Fig. 7.

For NTSR1-ELF-T4L, initial crystal screening was done at the Stanford Synchrotron Radiation Lightsource, beamline 12-2.

Figures were prepared in PyMOL (Schrödinger). Structural alignments were done with the 'align' command of PyMOL. Sigma-A weighted maps imported into PyMOL were generated by using the SigmaA program of the CCP4 suite and then converted to maps using the Phenix.mtz2map command line tool.

\section{References}

1. Deupi, X. \& Kobilka, B. K. Energy landscapes as a tool to integrate GPCR structure, dynamics, and function. Physiology (Bethesda) 25, 293-303 (2010).

2. Manglik, A. et al. Crystal structure of the mu-opioid receptor bound to a morphinan antagonist. Nature 485, 321-326 (2012).

3. White, J. F. et al. Structure of the agonist-bound neurotensin receptor. Nature 490, 508-513 (2012).

4. Choe, H. W. et al. Crystal structure of metarhodopsin II. Nature 471, 651-655 (2011).

5. Kruse, A. C. et al. Activation and allosteric modulation of a muscarinic acetylcholine receptor. Nature 504, 101-106 (2013).

6. Rasmussen, S. G. et al. Structure of a nanobody-stabilized active state of the beta(2) adrenoceptor. Nature 469, 175-180 (2011).

7. Rasmussen, S. G. et al. Crystal structure of the beta2 adrenergic receptor-Gs protein complex. Nature 477, 549-555 (2011).

8. Tanaka, K., Masu, M. \& Nakanishi, S. Structure and functional expression of the cloned rat neurotensin receptor. Neuron 4, 847-854 (1990).

9. Carraway, R. \& Leeman, S. E. The isolation of a new hypotensive peptide, neurotensin, from bovine hypothalami. J. Biol. Chem. 248, 6854-6861 (1973).

10. Griebel, G. \& Holsboer, F. Neuropeptide receptor ligands as drugs for psychiatric diseases: the end of the beginning? Nat. Rev. Drug Discov. 11, 462-478 (2012).

11. Kitabgi, P. Targeting neurotensin receptors with agonists and antagonists for therapeutic purposes. Curr. Opin. Drug Discov. Devel. 5, 764-776 (2002).

12. Shibata, Y. et al. Optimising the combination of thermostabilising mutations in the neurotensin receptor for structure determination. Biochim. Biophys. Acta 1828, 1293-1301 (2013).

13. Ballesteros, J. A. \& Weinstein, H. Integrated methods for the construction of three-dimensional models and computationla probing of structure-function relations in G protein-coupled receptors. Methods Neurosci. 25, 366-428 (1995).

14. Gully, D. et al. Biochemical and pharmacological profile of a potent and selective nonpeptide antagonist of the neurotensin receptor. Proc. Natl Acad. Sci. USA 90, 65-69 (1993).

15. Rovati, G. E., Capra, V. \& Neubig, R. R. The highly conserved DRY motif of class A G protein-coupled receptors: beyond the ground state. Mol. Pharmacol. 71, 959-964 (2007).

16. Warne, T. et al. Structure of a beta1-adrenergic G-protein-coupled receptor. Nature 454, 486-491 (2008).

17. Cherezov, V. et al. High-resolution crystal structure of an engineered human beta2-adrenergic G protein-coupled receptor. Science 318, 1258-1265 (2007).

18. Egloff, P. et al. Structure of signaling-competent neurotensin receptor 1 obtained by directed evolution in Escherichia coli. Proc. Natl Acad. Sci. USA 111, E655-E662 (2014).

19. Lee, S., Bhattacharya, S., Tate, C. G., Grisshammer, R. \& Vaidehi, N. Structural dynamics and thermostabilization of neurotensin receptor 1. J. Phys. Chem. B 119, 4917-4928 (2015)

20. Lin, S. W. \& Sakmar, T. P. Specific tryptophan UV-absorbance changes are probes of the transition of rhodopsin to its active state. Biochemistry 35, 11149-11159 (1996).

21. Pope, A., Eilers, M., Reeves, P. J. \& Smith, S. O. Amino acid conservation and interactions in rhodopsin: probing receptor activation by NMR spectroscopy. Biochim. Biophys. Acta 1837, 683-693 (2014).

22. Standfuss, J. et al. The structural basis of agonist-induced activation in constitutively active rhodopsin. Nature 471, 656-660 (2011). 
23. Tehan, B. G., Bortolato, A., Blaney, F. E., Weir, M. P. \& Mason, J. S. Unifying family A GPCR theories of activation. Pharmacol. Ther. 143, 51-60 (2014).

24. Martin, S., Botto, J. M., Vincent, J. P. \& Mazella, J. Pivotal role of an aspartate residue in sodium sensitivity and coupling to $G$ proteins of neurotensin receptors. Mol. Pharmacol. 55, 210-215 (1999).

25. Fenalti, G. et al. Molecular control of delta-opioid receptor signalling. Nature 506, 191-196 (2014).

26. Liu, W. et al. Structural basis for allosteric regulation of GPCRs by sodium ions. Science 337, 232-236 (2012).

27. Miller-Gallacher, J. L. et al. The 2.1A resolution structure of cyanopindololbound betal-adrenoceptor identifies an intramembrane $\mathrm{Na}+$ ion that stabilises the ligand-free receptor. PLoS ONE 9, e92727 (2014).

28. Zhang, C. et al. High-resolution crystal structure of human protease-activated receptor 1. Nature 492, 387-392 (2012).

29. Scheerer, P. et al. Crystal structure of opsin in its G-protein-interacting conformation. Nature 455, 497-502 (2008).

30. Shibata, Y. et al. Thermostabilization of the neurotensin receptor NTS1. J. Mol. Biol. 390, 262-277 (2009).

31. Tate, C. G. A crystal clear solution for determining G-protein-coupled receptor structures. Trends Biochem. Sci. 37, 343-352 (2012).

32. Sarkar, C. A. et al. Directed evolution of a G protein-coupled receptor for expression, stability, and binding selectivity. Proc. Natl Acad. Sci. USA 105, 14808-14813 (2008).

33. Schlinkmann, K. M. et al. Maximizing detergent stability and functional expression of a GPCR by exhaustive recombination and evolution. J. Mol. Biol. 422, 414-428 (2012).

34. Schlinkmann, K. M. et al. Critical features for biosynthesis, stability, and functionality of a $\mathrm{G}$ protein-coupled receptor uncovered by all-versus-all mutations. Proc. Natl Acad. Sci. USA 109, 9810-9815 (2012).

35. Franke, R. R., Konig, B., Sakmar, T. P., Khorana, H. G. \& Hofmann, K. P. Rhodopsin mutants that bind but fail to activate transducin. Science 250, 123-125 (1990)

36. Kobilka, B. K. Amino and carboxyl terminal modifications to facilitate the production and purification of a G protein-coupled receptor. Anal. Biochem. 231, 269-271 (1995).

37. Hellmich, M. R., Battey, J. F. \& Northup, J. K. Selective reconstitution of gastrin-releasing peptide receptor with G alpha q. Proc. Natl Acad. Sci. USA 94, 751-756 (1997)

38. Hartman, J. L. \& Northup, J. K. Functional reconstitution in situ of 5-hydroxytryptamine 2c (5HT2c) receptors with alphaq and inverse agonism of 5HT2c receptor antagonists. J. Biol. Chem. 271, 22591-22597 (1996).

39. Jian, X. et al. The bombesin receptor subtypes have distinct G protein specificities. J. Biol. Chem. 274, 11573-11581 (1999).

40. Cheng, Y. \& Prusoff, W. H. Relationship between the inhibition constant (K1) and the concentration of inhibitor which causes 50 per cent inhibition (I50) of an enzymatic reaction. Biochem. Pharmacol. 22, 3099-3108 (1973).

41. Inagaki, S. et al. Modulation of the interaction between neurotensin receptor NTS1 and Gq protein by lipid. J. Mol. Biol. 417, 95-111 (2012).

42. Chattopadhyay, A. \& Harikumar, K. G. Dependence of critical micelle concentration of a zwitterionic detergent on ionic strength: implications in receptor solubilization. FEBS Lett. 391, 199-202 (1996).

43. Chae, P. S. et al. Maltose-neopentyl glycol (MNG) amphiphiles for solubilization, stabilization and crystallization of membrane proteins. Nat. Methods 7, 1003-1008 (2010).

44. Caffrey, M. \& Cherezov, V. Crystallizing membrane proteins using lipidic mesophases. Nat. Protoc. 4, 706-731 (2009).

45. Landau, E. M. \& Rosenbusch, J. P. Lipidic cubic phases: a novel concept for the crystallization of membrane proteins. Proc. Natl Acad. Sci. USA 93, 14532-14535 (1996).

46. Cherezov, V. et al. Rastering strategy for screening and centring of microcrystal samples of human membrane proteins with a sub-10 microm size X-ray synchrotron beam. J. R. Soc. Interface 6(Suppl 5): S587-S597 (2009).

47. Hilgart, M. C. et al. Automated sample-scanning methods for radiation damage mitigation and diffraction-based centering of macromolecular crystals. J. Synchrotron Radiat. 18, 717-722 (2011).

48. Kabsch, W. XDS. Acta Crystallogr. D Biol. Crystallogr. 66, 125-132 (2010)

49. Evans, P. R. \& Murshudov, G. N. How good are my data and what is the resolution? Acta Crystallogr. D Biol. Crystallogr. 69, 1204-1214 (2013).

50. Winn, M. D. et al. Overview of the CCP4 suite and current developments. Acta Crystallogr. D Biol. Crystallogr. 67, 235-242 (2011).
51. Adams, P. D. et al. PHENIX: a comprehensive Python-based system for macromolecular structure solution. Acta Crystallogr. D Biol. Crystallogr. 66, 213-221 (2010).

52. Winn, M. D., Isupov, M. N. \& Murshudov, G. N. Use of TLS parameters to model anisotropic displacements in macromolecular refinement. Acta Crystallogr. D Biol. Crystallogr. 57, 122-133 (2001).

53. Painter, J. \& Merritt, E. A. Optimal description of a protein structure in terms of multiple groups undergoing TLS motion. Acta Crystallogr. D Biol. Crystallogr. 62, 439-450 (2006).

54. Emsley, P., Lohkamp, B., Scott, W. G. \& Cowtan, K. Features and developmen of Coot. Acta Crystallogr. D Biol. Crystallogr. 66, 486-501 (2010).

55. Chen, V. B. et al. MolProbity: all-atom structure validation for macromolecular crystallography. Acta Crystallogr. D Biol. Crystallogr. 66, 12-21 (2010).

\section{Acknowledgements}

This research was supported by the Intramural Research Program of the National Institutes of Health, National Institute of Neurological Disorders and Stroke. We thank the staff at the General Medicine and Cancer Institute's Collaborative Access Team (GM/CA-CAT) beamline at the Advanced Photon Source, Argonne National Laboratory; and personnel at the Stanford Synchrotron Radiation Lightsource, beamline 12-2, for their assistance during data acquisition. GM/CA at APS has been funded in whole or in part with Federal funds from the National Cancer Institute (ACB-12002) and the National Institute of General Medical Sciences (AGM-12006). This research used resources of the Advanced Photon Source, a U.S. Department of Energy (DOE) Office of Science User Facility operated for the DOE Office of Science by Argonne National Laboratory under Contract No. DE-AC02-06CH11357. Use of the Stanford Synchrotron Radiation Lightsource, SLAC National Accelerator Laboratory, is supported by the U.S Department of Energy, Office of Science, Office of Basic Energy Sciences under Contract No. DE-AC02-76SF00515. The SSRL Structural Molecular Biology Program is supported by the DOE Office of Biological and Environmental Research and by the National Institutes of Health, National Institute of General Medical Sciences (including P41GM103393). The production of NTSR1 baculoviruses was done at the Protein Expression Laboratory, Leidos, National Cancer Institute, Frederick, MD, USA. DNA sequence analysis was performed in part by the National Institute of Neurological Disorders and Stroke DNA Sequencing Facility. Peptides were synthesized at the Center for Biologics Evaluation and Research (Food and Drug Administration, Bethesda, MD, USA). We thank Di Xia (Center for Cancer Research, NCI) for review of the X-ray data and coordinates.

\section{Author contributions}

B.E.K. expressed and purified NTSR1 crystallization constructs, conducted pharmacological experiments, optimized the purification procedure, performed crystallization trials, collected diffraction data, solved and refined the structures. J.F.W. expressed and purified NTSR1 and G protein, tested NTSR1 mutants for stability and conducted pharmacological experiments. P.S. performed the molecular biology tasks. R.G. performed the crystallization experiments, assisted with data collection and was responsible for the overall project strategy. The manuscript was written by B.E.K and R.G.

\section{Additional information}

Accession codes. Coordinates and structure factors for NTSR1-LF-T4L and NTSR1ELF-T4L are deposited in the Protein data Bank under the accession codes 4XES and 4XEE, respectively.

Supplementary Information accompanies this paper at http://www.nature.com/ naturecommunications

Competing financial interests: The authors declare no competing financial interests.

Reprints and permission information is available online at http://npg.nature.com/ reprintsandpermissions/

How to cite this article: Krumm, B. E. et al. Structural prerequisites for G-protein activation by the neurotensin receptor. Nat. Commun. 6:7895 doi: 10.1038/ncomms8895 (2015).

This work is licensed under a Creative Commons Attribution 4.0 International License. The images or other third party material in this article are included in the article's Creative Commons license, unless indicated otherwise in the credit line; if the material is not included under the Creative Commons license, users will need to obtain permission from the license holder to reproduce the material To view a copy of this license, visit http://creativecommons.org/licenses/by/4.0/ 